\title{
El Trabajo Docente Frente Al Blended-Learning
}

Abstracción Metacognitiva

Esta reflexión hace parte de los alcances bibliográficos de la investigación titulado: Caracterización de las estrategias metacognitivas de los docentes del programa de contaduría pública de la Universidad Santo Tomas, en BlendedLearning.

Es lugar común afirmar que los tiempos cambian, y ello es fácilmente observable en temas como los tecnológicos, sin embargo, no siempre se hace visible en temas asociados a la educación, sin embargo, el que no sea fácilmente perceptible, no implica que las transformaciones no involucren la educación. De hecho, según (KLIMENO, 2009), la necesidad de desarrollar una nueva manera de aprender está determinada por las características de la misma época postmoderna atravesada por el paradigma del pensamiento complejo.

Con ello se quiere significar la preocupación de conceptos asociados a lo educativo tengan relación con la época que les corresponde; esto implica el aprendizaje, el papel de los actores, el currículo, la evaluación, principalmente. Un ejemplo de ello se observa cómo según (KLIMENO, 2009) en la modernidad, el conocimiento fue concebido como una verdad absoluta, una réplica exacta de la realidad, que debía ser conservado de manera inalterable

En esa misma línea se podría afirmar que lo postmoderno exige una nueva forma de concebir la educación, asociado ya no a lo absoluto sino a conocer la realidad tal como es, es decir, relativa. Por tanto, entre los cambios habría que pasar de las estrategias meramente cognitivas (propias de la racionalidad moderna) y entendidas según (HERRERA 2009) como estrategias de repaso, elaboración y organización de información, además del pensamiento crítico a estrategias metacognitivas. 
Según (HERRERA 2009), por estrategias metacognitivas habrá de entenderse aquellas asociadas a la planificación, control y regulación de las actividades realizadas durante el aprendizaje.

En este orden de ideas, es importante el concepto de blended learning: que de manera natural se entiende como la educación combinada o educación semipresencial, donde se combina encuentros presenciales y actividades online 0 virutales, claro esto conlleva diferentes aspectos de discusión desde su propia conceptualización puramente etimológica o semántica hasta su práctica, pero dejemos tal caso para otro espacio, nos centraremos en algunos aspectos puramente metacognitivos más cercanos al docente y la enseñanza que desde el estudiante y su aprendizaje.

En una visión diferente van los planteamientos de la modernidad líquida, (BAUMAN 2004), quien afirma: los códigos y conductas que uno podía elegir como puntos de orientación estables, y por los cuales era posible guiarse, escasean cada vez más en la actualidad, de manera simple lo que se consideraba verdadero y absoluto puede que ya no lo sea, o más sincero la forma de enseñar ha cambiado y seguirá cambiando, no porque no marche si no porque estamos aprendiendo de forma diversa.

Al tener el profesor que responder de una manera distinta, por los retos de la modernidad líquida, es que se desarrolla, entre otras, el B-Learning como herramienta de inclusión, donde el papel del docente se considera entre mediador y orientador; cambia la forma de resolución de problemas, la retroalimentación con el estudiante puede ser presencial o virtual, el uso de Tics y redes sociales como apoyo, la participación en el diseño de entornos virtuales, como se hace el trabajo individual y en equipo, capacitación en herramientas tecnológicas, las evaluaciones, entre otras.

Para estudiar este asunto, por cierto, de naturaleza compleja, hay que contemplar criterios desarrollados por diversos autores. Al respecto, (MORAN, 2012) hace referencia específica a las dimensiones que atraviesa toda 
experiencia educativa, aquí se muestran tres dimensiones que se trabajan tanto en el espacio presencial y online.

- Configuración del espacio y del tiempo: En esta dimensión se integran los aspectos relativos al uso del tiempo y del espacio en que se realiza en cada uno de los entornos.

- Proceso de enseñanza y de aprendizaje: Esta dimensión hace referencia a los aspectos específicos de la propuesta de enseñanza-aprendizaje que caracteriza a la formación en un entorno presencial y en un entorno online.

- Socialización: Con esta dimensión se hace referencia al contacto que establecen quienes participan de la formación. El contacto mediante el cual alumnos y docentes se interrelacionan entre sí y adquieren la experiencia necesaria para interrelacionarse con el prójimo.

Estos aspectos tienen relación directa con el trabajo de combinación de las TIC, que se puede entender como los niveles o etapas por los que se atraviesa en este proceso de integración. De igual forma (Gros \& Contreras, 2006), citado por (MORAN, 2012) no deja de lado la alfabetización digital entendida como:

La capacidad para realizar juicios de valor acerca de la información que se obtiene en línea, destrezas de lectura y comprensión en un entorno de hipertexto dinámico no secuencial, destrezas de construcción del conocimiento con tecnologías, habilidades de búsqueda, gestión de la comunicación, capacidad para comprender un problema y seguir un conjunto de pasos en el diseño de propuestas didácticas con tecnologías y valoración de las herramientas del sistema como apoyo a los formatos tradicionales del contenido.

Se entiende que este no es el objetivo principal, el de valorar las habilidades de los docentes en Tics, pero puede que se de algún acercamiento en este sentido. 
En la exploración bibliográfica de estudios cercanos a la investigación y en búsqueda de criterios que soporten un instrumento se encontró en, (Pallisé, González, Verges, \& Daniel, 2016) lo siguiente que llama la atención en cuanto a criterios en el instrumento empleado en dicha investigación.

Se consideraron diez dimensiones para cada uno de los grados con docencia semipresencial: la conceptualización de la semipresencialidad y su contextualización, la valoración de la experiencia a nivel institucional, las estrategias seguidas, los recursos que se han precisado, el posible ahorro institucional, la metodología docente aplicada, el perfil del profesorado, el reconocimiento docente, la formación del profesorado y el perfil del alumnado.

Los anteriores criterios son más de evaluación institucional y de la dirección o dirección de las instituciones educativas, ya en criterios más cercanos a los docentes en el mismo documento (Pallisé, González, Verges, \& Daniel, 2016) se encontró que:

Para ello, se incluyen 32 ítems sobre la aplicabilidad de la docencia semipresencial en las diferentes ramas de conocimiento, aspectos relacionados con el reconocimiento institucional, la metodología docente, la evaluación, los materiales docentes, los recursos tecnológicos, el perfil y la formación del profesorado, el reconocimiento de la tarea docente, la tipología del estudiante en la docencia semipresencial y las actitudes y valores que le son necesarios.

Así con estos criterios puede ser posible hacer un análisis o caracterización mas cercana frente al trabajo docente y el blended learning, tema que seguirá en la mira ya no tanto por su novedad sino por su importancia en la educación, se quiere dejar aquí algunos enunciados o supuestos que merecen atención y en especial para aquello que estén inmersos en temas pedagógicos y de educación:

\section{REFERENCIAS}


BAUMAN Z. (2004). La modernidad líquida. Fondo de Cultura Económica. México. 230p.

HERRERA L. (2009). Estrategias de aprendizaje en estudiantes universitarios. Educación y Educadores, 2009, Volumen 12, Número 3, pp. 75 - 98. P.76. Editorial Universidad de la Sabana.

http://site.ebrary.com.bdatos.usantotomas.edu.co:2048/lib/bibliotecaustasp/read er.action?doclD $=10566169 \& p p g=3$

KLIMENO O. (2009). Aprender cómo aprendo: la enseñanza de estrategias metacognitivas. Educación y Educadores, 2009, Volumen 12, Número 2, pp. 11-28. P12. Universidad de la Sabana.

http://site.ebrary.com.bdatos.usantotomas.edu.co:2048/lib/bibliotecaustasp/read er.action?doclD $=10565581 \& \mathrm{ppg}=3$

MORAN, L. (2012). Blended Learning, Desafio y oportunidad para la educaciòn actual . Edutec revista electronica de tecnologia educativa.

Pallisé, J. S., González, C. B., Verges, C. B., \& Daniel, M. B. (2016). LA SEMIPRESENCIALIDAD EN EDUCACIÓN SUPERIOR: CASOS DE ESTUDIO EN LOS GRADOS DE LA UNIVERSIDAD DE BARCELONA. EDUTEC, LA SEMIPRESENCIALIDAD EN EDUCACIÓN SUPERIOR: CASOS DE ESTUDIO EN LOS GRADOS DE LA UNIVERSIDAD DE BARCELONA. Obtenido de file://C:/Users/edgar/Desktop/Investigación\%20estrategias\%20metacognitivas/la\%20 semipresencialidad\%20en\%20la\%20educaciòn\%20superior\%20barcelona.pdf 